\title{
Simulation model of an eyeball based on finite element analysis on a supercomputer
}

\author{
Eiichi Uchio, Shigeaki Ohno, Joju Kudoh, Koki Aoki, Lech Tomasz Kisielewicz
}

\section{Department of Ophthalmology, Yokohama City University School of Medicine, Yokohama, Japan \\ E Uchio \\ S Ohno \\ J Kudoh}

Aoki Eye Clinic, Sapporo, Japan

K Aoki

Nihon ESI, Tokyo, Japan

L T Kisielewicz

Correspondence to: Eiichi Uchio, MD, Department of

Ophthalmology, Yokohama City University School of Medicine, 3-9 Fuku-ura, Kanazawa, Yokohama 236-0004, Japan.

Accepted for publication 25 June 1999

Table 1 Experimental set up

Sample preparation (strip samples of cornea and sclera from human cadaver eyes) $\downarrow$

Loading of strip samples with different compressive stresses and taking photograph from above

Loading of strip samples with different compressive

Measurement of stress-strain relations and determination of Poisson's ratio $\downarrow$

Determination of geometry of eyeball model based on measured and reported mechanical properties

Finite element mesh creation

Missile impact simulation at different impacting velocities
Microsurgical techniques and closer surveillance of complications have improved the prognosis dramatically. Nevertheless, it is still important to analyse the causes and mechanisms of ocular trauma in order to identify preventable factors. Of the ocular injuries in adults seen at hospital ophthalmic casualty departments, $35-70 \%{ }^{1-5}$ are occupational. This presumably reflects the vulnerability of the eye to injury, but may also be an indicator of the inadequacy of present preventive measures. In contrast with most occupational ocular injuries, intraocular foreign body (IOFB) injuries constitute an immediate threat to vision and usually carry a poor visual prognosis. To our knowledge, no study has ever investigated the detailed mechanism of these injuries. Recent developments in computer technology have enabled numerical simulations based on finite element analysis (FEA) to analyse the biomechanical response of the human body and the underlying mechanisms of injury. ${ }^{6}$

In this study, a simulation model of the human eye, which was set up based on information obtained from cadaver eyes, was developed using a specific software program for a supercomputer. To determine the physical and mechanical conditions of impacting foreign bodies causing IOFB injuries, three dimensional FEA was applied.

\section{Materials and methods}

SAMPLE PREPARATION

A diagram of the experimental setup is summarised in Table 1. After proper informed consent was obtained, human cadaver eyes (three pairs) were enucleated between 8 and 24 hours after death and stored in a refrigerator at $4^{\circ} \mathrm{C}$, and experiments were conducted within 48 hours of enucleation. The ages of the patients from whom the eyes were taken were 64,78 , and 81 years. To prepare a test sample, the conjunctiva was removed. The globe was then bisected at the equator. Strip samples of sclera were taken from just around the corneoscleral limbus after trephination of the cornea using a $9 \mathrm{~mm}$ trephine. Uniform strips of sclera were cut using parallel razor blades set to cut strips that were $2.5 \mathrm{~mm}$ wide and $9.0 \mathrm{~mm}$ long. Then they were stored at $4^{\circ} \mathrm{C}$ until testing, which was always within 3 hours of sample preparation. Two strips were taken from each globe. Some swelling of the tissue is likely to 

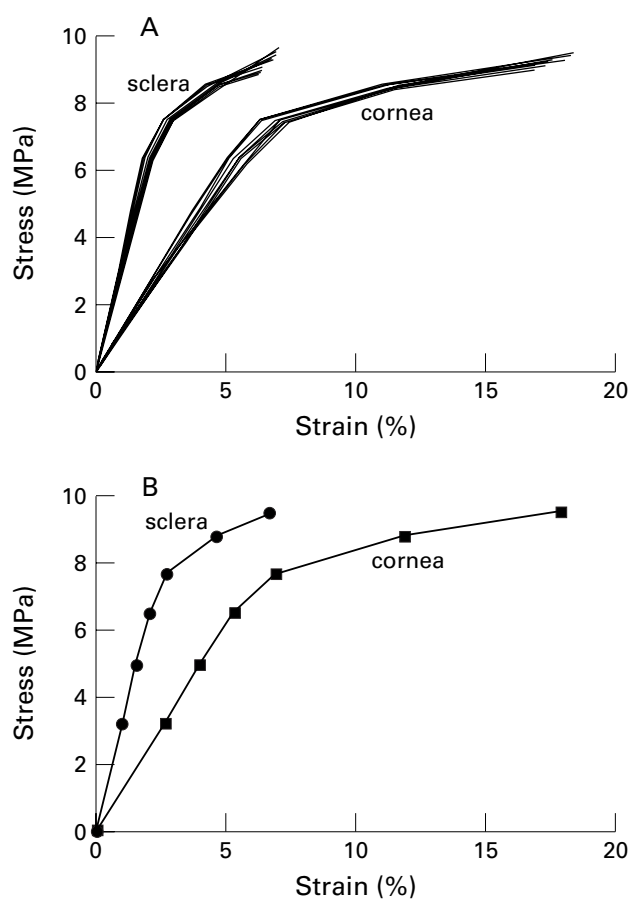

Figure 1 Stress-strain curves for cornea and sclera. Each line represents the value from 12 corneal or scleral samples (A). Stress-strain curve for the simulation model is derived from experimental values and the data of past reports. Penetrating ocular injury is assumed to occur at a strain of $18.0 \%$ in cornea and $6.8 \%$ in sclera (B).

have occurred while the samples were stored in saline solution, but this is estimated to be no more than $10 \%$ of the initial volume. Just after trephination of the cornea, central corneal thickness was measured by pachymetry (AL1000, Tomei, Nagoya, Japan) and the swollen corneas were dehydrated to a thickness of 400 and $540 \mu \mathrm{m}$ by dropping $95 \%$ glycerin on them. Two parallel vertical strips with a length of $9.0 \mathrm{~mm}$ and a width of $2.5 \mathrm{~mm}$ were excised from each cornea and stored in a wet chamber.

MEASUREMENT OF STRESS-STRAIN RELATION AND POISSON'S RATIO OF HUMAN CORNEA AND SCLERA A method similar to that described previously ${ }^{7}$ was used to measure stress-strain relation of cornea and sclera. Definitions of stress and strain are given elsewhere. ${ }^{8}$ In brief, if a bar is subjected to uniform tension or compression, the internal force is referred to as stress defined as:

$$
\text { stress }(\sigma)=\text { load } / \text { cross sectional area }
$$

Table 2 Poisson's ratio of human corneal and scleral samples

\begin{tabular}{llll}
\hline & & \multicolumn{2}{c}{ Poisson's ratio } \\
\cline { 3 - 4 } Cases & Sample no & Cornea & \multirow{2}{*}{ Sclera } \\
\hline Age: 64 years & 1 and 2 & 0.435 & 0.470 \\
Female & 3 and 4 & 0.400 & 0.480 \\
Age: 78 years & 5 and6 & 0.430 & 0.460 \\
Female & 7 and 8 & 0.445 & 0.475 \\
Age: 81 years & 9 and 10 & 0.395 & 0.455 \\
Male & 11 and 12 & 0.415 & 0.480 \\
Mean & & 0.420 & 0.470
\end{tabular}

Two strips of cornea and sclera were taken from each globe. Mean of values from paired samples is given.
If such a bar is subjected to a load, it will change in length and the non-dimensional deformation is referred to as strain defined as: strain $(\varepsilon)=$ change in length/original length

If a bar of homogeneous material is subjected to a tensile load and increases in length under some friction, it will exhibit a reduction in dimensions laterally. If the bar is maintained within the elastic limits of the material, the ratio of the strains will be a constant of:

Poisson's ratio $(v)=$ lateral strain/ longitudinal strain

Poisson's ratio ranges between 0 and 0.5 according to the compressibility of the material. Poisson's ratio of an incompressible material such as water is 0.5 . Each sample was affixed to two flat-faced steel anvils with cyanoacrylate adhesive (Alon-Alfa, Toa Gosei, Tokyo, Japan). The glued sample was then transferred to the extensometer. The sample was immersed in a thermoregulated $\left(37^{\circ} \mathrm{C}\right)$ mineral oil bath to maintain constant hydration during the tests. A compressive stress of 0.2 $\mathrm{MPa}$ was then applied to ensure firm contact between the sample and holder, and 30 minutes was allowed for stabilisation. This point was used as the reference (strain $=\varepsilon=0$ ), from which all subsequent strains were measured. In order to determine Poisson's ratio (v), the sample was photographed from above, under magnification, with different loading conditions according to the method reported previously. ${ }^{9}$ The cross sectional area of the sample was thus determined both before $\left(A_{\mathrm{s} 0}\right)$ and after $\left(A_{\mathrm{s}}\right)$ compressive stress. These areas, in conjunction with the measured compressive strain, yield a value of Poisson's ratio:

$$
v=\left(\left(\mathrm{A}_{\mathrm{s}} / \mathrm{A}_{\mathrm{s} 0}\right)[1 / 2]-1\right) / \varepsilon
$$

The measured areas correspond to compressive stresses of 0.2 and $0.4 \mathrm{MPa}$, respectively. All stresses are computed based on the area $A_{s 0}$. The sample was then stressed by placing increasing weights in the pan to measure the stress-strain relation. Each sample was tested three times at five given levels of stress, between 3.25 and $8.77 \mathrm{MPa}$, and the mean strain was determined. Then, the sample was further stressed at over 9.00 MPa until it ruptured.

\section{MATERIAL PROPERTIES AND GEOMETRY OF THE} MODEL

The stress-strain curves for corneal and scleral samples are presented graphically in Figure 1A. Increasing levels of stress produce larger amounts of strain. Rupture occurred at a strain between 17.2 and $18.7 \%$ (mean $18.0 \%$ ) and stress between 9.20 and $9.70 \mathrm{MPa}$ (mean 9.45 $\mathrm{MPa}$ ) in the cornea, and at a strain between 6.4 and $7.1 \%$ (mean $6.8 \%$ ) and stress between 9.10 and $9.90 \mathrm{MPa}$ (mean 9.49 $\mathrm{MPa}$ ) in the sclera. The stress-strain curve in the simulation study represents a product of the properties derived from the experimental data obtained (Fig 1B). The procedure to determine Poisson's ratio was followed in 12 corneal and scleral samples, for compressive stresses of 0.2 and $0.4 \mathrm{MPa}$, and the results are given in Table 2 . The range of compressive stresses was 


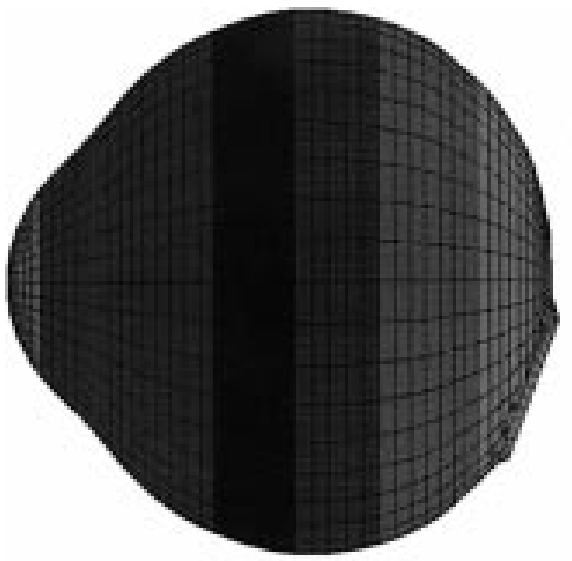

A

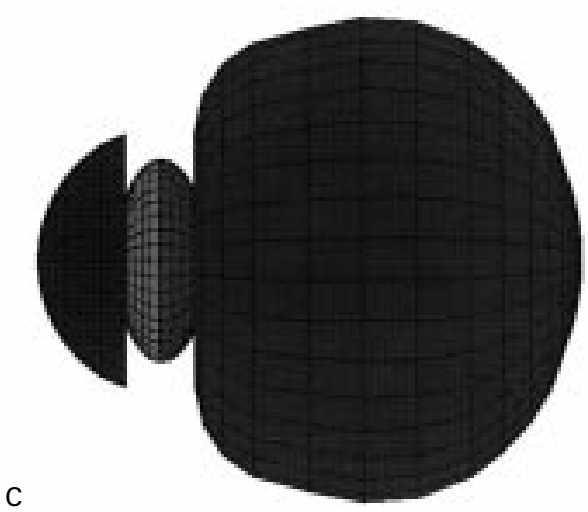

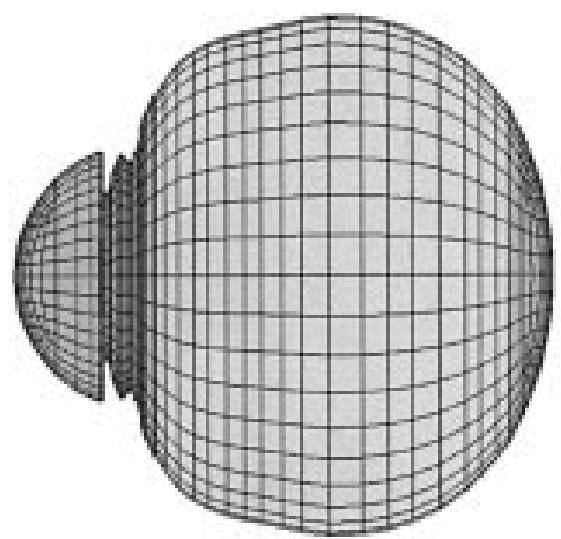

B

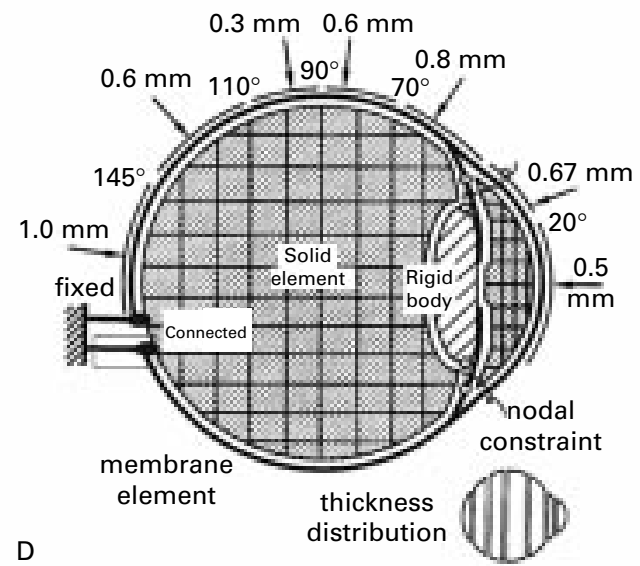

Figure 2 Meshing principles of the eye. The model of the human eye is composed of three layers, outer ( $A$; cornea and sclera (superficial layer)), middle (B; cornea and sclera (deep layer), iris, ciliary body, choroid, and retina), and inner (C; aqueous humour, lens, and vitreous). Mesh principle in the cross sectional view is indicated (D).

determined according to past reports. ${ }^{8} 1011$ Measurements showed that this ratio varied between 0.395 and 0.480 . A mean value of 0.420 was used for cornea and 0.470 for sclera in this study. From these results and assumptions, it is assumed that rupture occurs at a strain of $18.0 \%$ in cornea and $6.8 \%$ in sclera, and at a stress of $9.4 \mathrm{MPa}$ for both tissues. The corneal surface has an aspheric shape, being steeper centrally and flatter peripherally. For simplicity, the cornea was assumed to be spherical, with a central thickness of $0.5 \mathrm{~mm}$ and a central radius of curvature of $7.8 \mathrm{~mm}$. Depth of the anterior chamber was assumed to be $3.1 \mathrm{~mm}$. The other variables of the model eye were as follows. The lens was assumed to be biconvex with a central thickness of $3.6 \mathrm{~mm}$, an anterior radius of curvature of $10.0 \mathrm{~mm}$, and a posterior radius of curvature of $6.0 \mathrm{~mm}$. The length of the vitreous body and the posterior curvature of the retina were assumed to be 17.0 and $12.0 \mathrm{~mm}$. The mass densities of ocular tissues were derived from past reports and assumed to be as follows ${ }^{912}{ }^{13}$ : cornea, 1.149; sclera, 1.243; vitreous, 1.002; aqueous humour, 1.000. In the scope of the investigation reported here, it is believed that the elastic properties of the lens have little influence on the expected results. Thus, the lens was modelled as a rigid non-deformable body.

ELEMENT TYPE

The general meshing principles are described in Figure 2. The model of the human eye is composed of three layers; outer (cornea and sclera (superficial layer)), middle (cornea and sclera (deep layer), iris, ciliary body, choroid, and retina), and inner (aqueous humour, lens, and vitreous). The cornea and sclera were modelled as membranous elements. The lens was modelled as a rigid body, and the vitreous as a solid mass with hydrostatic pressure of 20 $\mathrm{mm} \mathrm{Hg}(2.7 \mathrm{kPa})$. The cornea was loaded with the intraocular pressure on the posterior surface and with the atmospheric pressure on the anterior surface. The loading produced by

Table 3 Number of elements used for FEA model

\begin{tabular}{lrr}
\hline Anatomic component & Shell & Solid \\
\hline Cornea & 380 & 0 \\
Sclera & 1580 & 0 \\
Iris, ciliary body, and choroid & 1040 & 0 \\
Lens & 680 & 0 \\
Aqueous humour & 0 & 288 \\
Vitreous & 0 & 2664 \\
Total & 3680 & 2952 \\
\hline
\end{tabular}


the eyelids was ignored. Using these principles, modules of the Hypermesh (Altair Engineering, Ltd, Tokyo, Japan $)^{14}$ were used for solid modelling, geometric construction, and finite element mesh creation, as depicted in Figure 2. The number of elements is defined in Table 3. The boundary condition at the junction of the cornea and limbus was difficult to define because the mechanical properties of the limbus are not well described. Since the limbus is presumably much stiffer than the cornea and the resistance of the cornea to bending is not very high, ${ }^{9}$ the peripheral nodes of the cornea were allowed to rotate freely about an axis tangential to the circle containing the boundary nodes. Contacts between the other parts of the model can be accounted for with a series of search algorithms and can be modelled with assumptions on the friction between the areas in contact.

\section{SET UP OF IMPACT MISSILE}

Since most of the missiles encountered in the series were rather blunt (data not shown), the missile shape used in the simulation was blunt, as shown in Figure 3. This missile was a decagohedron that was composed of a cuspidal hexahedron and a rectangular parallelepiped. The top and bottom of the missile were squares, and the side of the top square was one third of that of the bottom square. As clinical data were collected after the event of foreign body impact and penetration of the eyeball, there is no information about the impact velocity. Instead, some typical impact velocities could be deduced from industrial accidents occurring during the operation of grinding or glass cutting machinery. These machines contain rotating components that occasionally eject debris, causing ocular injuries. According to the specifications distributed by industrial machine manufacturers, maximum missile impact velocities were deduced depending on the maximum rotations per minute ( $\mathrm{rpm}$ ) and the diameter of the tools. ${ }^{15} 16$ For simplification, angular momentum of the missile was ignored. The missile velocity varied between 47 and $74 \mathrm{~m} / \mathrm{s}$; however, the velocity was mostly between 56 and $62 \mathrm{~m} / \mathrm{s}$ (unpublished

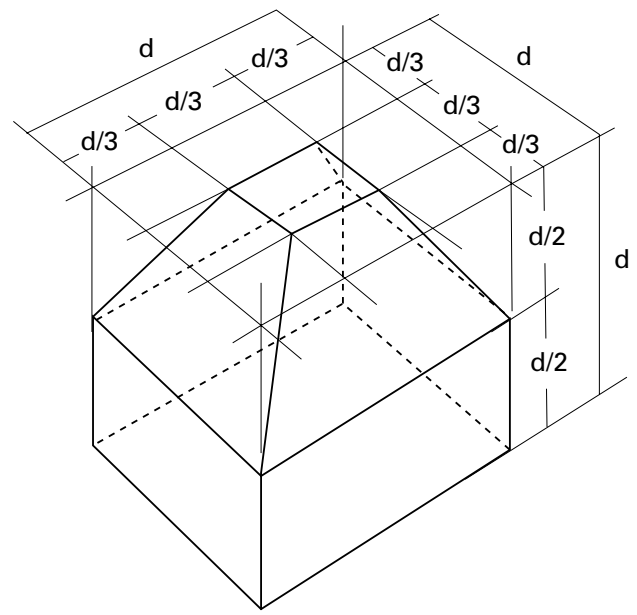

Figure 3 Missile shape. The missile shape used in the simulation is blunt. Size of the missile is indicated as $d$.
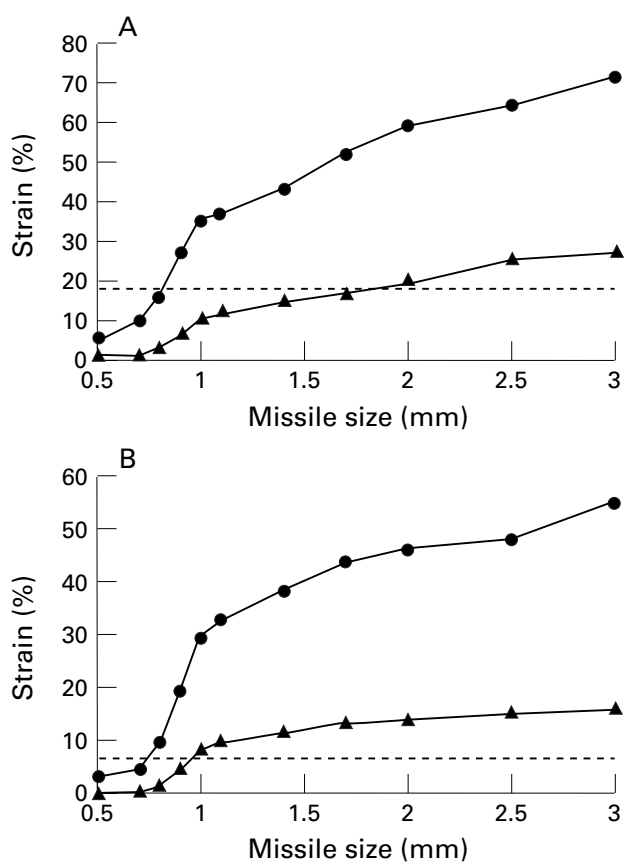

Figure 4 Axial strain and axial size curve of cornea (A) and sclera (B). The threshold of rupture is $18.0 \%$ for

cornea and $6.8 \%$ for sclera as indicated by the broken line. The two conditions of different velocities of missiles, $30 \mathrm{~m} / \mathrm{s}$ $(H)$ and $60 \mathrm{~m} / \mathrm{s}(\mathfrak{F})$, are demonstrated.

data). Thus, a typical impact velocity of $60 \mathrm{~m} / \mathrm{s}$ and a lower velocity of $30 \mathrm{~m} / \mathrm{s}$ were used in the parametric study. From considering the clinical data, the range of missile weight in this simulation was set at $0.05-0.30 \mathrm{~g}$. The size of impacting missiles in this simulation was also varied between 0.5 and $3.0 \mathrm{~mm}$.

MISSILE IMPACT

All the simulations in this study were solved by Cray Y/MP Supercomputer (Canon Supercomputing, SI, Co, Ltd, Tokyo, Japan) using the FEA program of PAM-CRASH (Nihon ESI, Co, Ltd, Tokyo, Japan). This code is a non-linear explicit finite element code which is used widely in the automotive industry for dynamic crash simulation. The simulation can be performed on a supercomputer, a workstation or a personal computer of any manufacturer installed with Windows NT. Minimum memory requirement was 17 megabites, if the simulation was carried out on a standard workstation. The missiles designed for this study as shown above were shot and set to impact on the surface of the cornea or the sclera at velocities of 30 and $60 \mathrm{~m} / \mathrm{s}$. All simulation situations were completed within 2 minutes (CPU time). Strain and size relations were displayed graphically. The terminology of ocular trauma used in this study is based on the standardised classification of ocular trauma recommended by the United States Eye Injury Registry and the International Society of Ocular Trauma. ${ }^{17}$

\section{Results}

Figure 4 shows the simulated strain and size curves of cornea (A) and sclera (B). The two conditions of different velocities of missiles, 30 


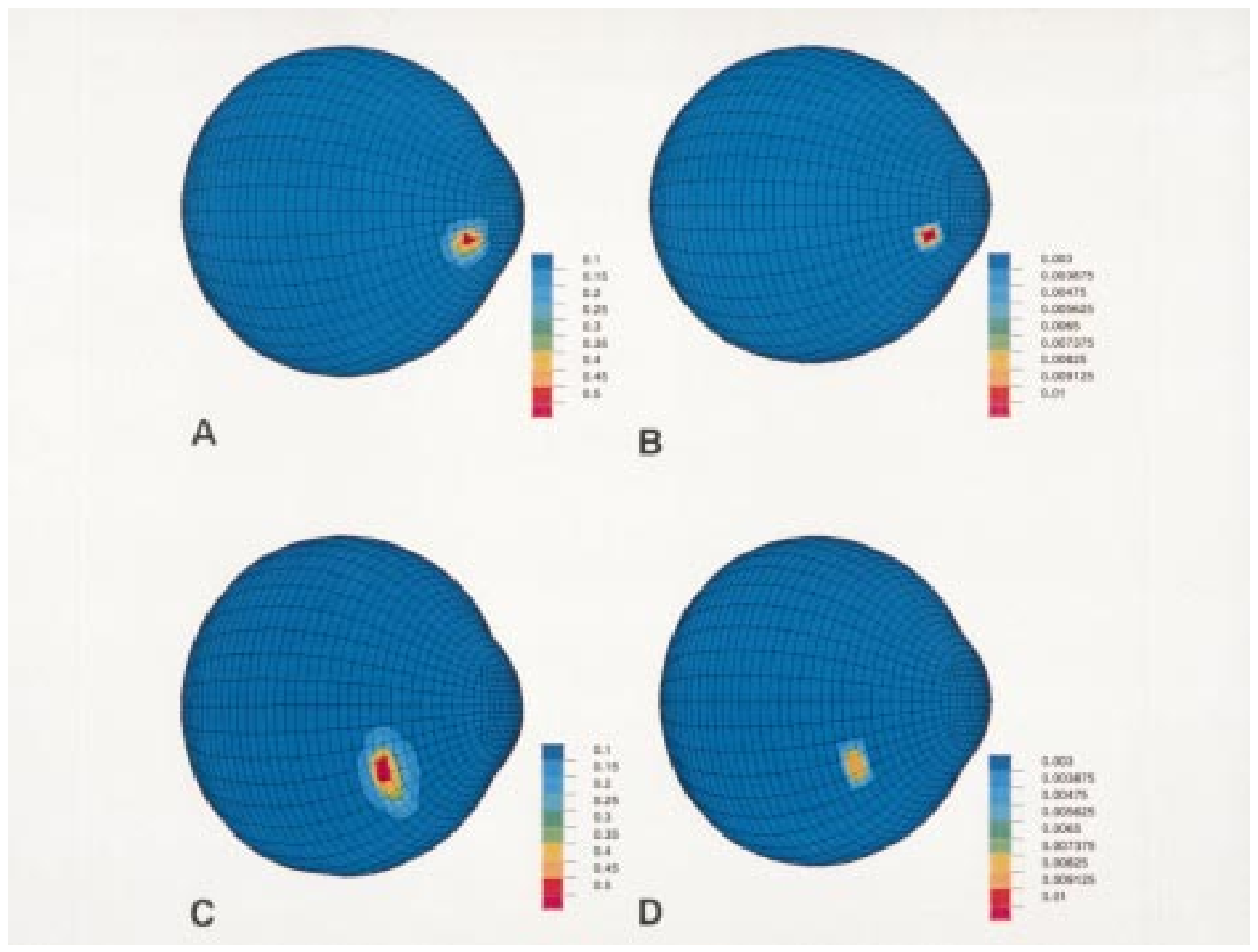

Figure 5 Example of missile impacts on cornea and sclera. Simulation in four situations, 3.0, 60, cornea (size (mm), velocity ( $\mathrm{m} / \mathrm{s})$, impacted tissue) (A), $0.5,60$, cornea (B), 3.0, 60, sclera $(C)$ and 0.5, 60, sclera (D), is displayed. Colour bar indicates axial strain. Rupture is represented in $A$ and $C$.

and $60 \mathrm{~m} / \mathrm{s}$, are demonstrated in each figure. Precise identification of the threshold of penetrating ocular injury is given as follows. For cornea, the lower limits of missile size to cause rupture at velocities of 30 and $60 \mathrm{~m} / \mathrm{s}$ were 1.95 and $0.82 \mathrm{~mm}$. The sizes of missiles causing scleral rupture were 0.95 and $0.75 \mathrm{~mm}$ at velocities of 30 and $60 \mathrm{~m} / \mathrm{s}$. In Figure 4, the broken line represents the threshold of rupture. Examples of impact simulations for cornea or sclera are shown in Figure 5.

\section{Discussion}

Stress-strain tests were performed to ascertain the elastic property of human cornea and sclera. The stress-strain curves obtained for corneal and scleral tissue (Fig 1A) are similar to those in past reports. ${ }^{10}{ }^{18}$ Values of Poisson's ratio obtained from our experiment were between 0.395 and 0.480 , which are also consistent with those in past studies. ${ }^{8} 9111819$

Several finite element based computer models of the cornea ${ }^{20}$ and corneoscleral limbus ${ }^{18}$ have been reported. The former model is a linear isotropic model and the latter is a non-linear, anisotropic model. Although these studies have demonstrated the biomechanical properties of the cornea and corneoscleral limbus, these models are of cornea only, and other ocular structures such as sclera, lens, and vitreous are not included. The number of elements in these studies was less than 750 , which is small compared with the present study (6632 in total). The other important benefit of computer models to analyse biomechanical experiments and to quantify mechanical variables is that they may in the long term reduce the need for animal studies, which are being restricted more and more on ethical grounds. The validity of computer models depends on the quality of the available biomechanical information. Past studies of the mechanical properties of animal and human cadaver eyes ${ }^{911} 13^{2122}$ are useful to provide detailed information concerning static and dynamic ocular tissue properties. Moreover, we measured the stress-strain relation of cornea and sclera using human cadaver eyes, since this information is of critical importance for a simulation model. At present, there exists no generally accepted injury model for the whole eyeball. Although this study seems well suited as a human ocular injury model, future studies should address several issues: (a) methods to produce more accurate models of the connection between the eyeball and the skull via ocular adnexae should be addressed; (b) the shear effect brought about by missiles with other forms, such as a cone or a tetrahedron, could become nonnegligible in a more detailed simulation and should be included in the model. 
Intraocular foreign bodies have been reported to comprise $11-22 \%{ }^{152324}$ of ocular injuries, $44 \%{ }^{4}$ of penetrating ocular injuries, and $82 \%{ }^{25}$ of occupational ocular injuries. Of the injured workers, only $33 \%$ were reported to have safety goggles supplied at their place of work. ${ }^{26}$ However, owing to the loss of clear vision, these protectors are not always used in Japan. Further enforcement of safety precautions is needed in industry.

We have determined the threshold of penetrating ocular injury with foreign bodies of different size and velocity in a FEA supercomputer simulation study. The threshold size of missiles causing IOFB injury ranged from 0.75 to $0.95 \mathrm{~mm}$. However, the lower limit of missile size to cause rupture in the cornea at a velocity of $30 \mathrm{~m} / \mathrm{s}, 1.95 \mathrm{~mm}$, was an exception. This result leads to the hypothesis that most IOFB injuries are caused at a velocity of more than 30 $\mathrm{m} / \mathrm{s}$. The fact that the calculated missile velocity of grinding or glass cutting machinery was between 56 and $62 \mathrm{~m} / \mathrm{s}$ supports this hypothesis. Also we have no detailed report of the distribution of size or weight of IOFB in clinical cases. Our results suggest that our FEA model has potential usefulness as a simulation tool for the ocular injury, and it may provide useful information for protective measures against industrial and traffic ocular injuries. It is also possible to use our FEA model in the simulation of other ocular injuries such as airbag impact. This work was supported by a grant in aid for encouragement of
young scientists (09771456) from the Ministry of Education, young scientists (09771456) from the Ministry of Education,
Science, Sports and Culture of Japan. We thank Dr W Gray for Science, Sports and Culture of Japar
critical review of this manuscript.

1 Johnston SS. Symposium on ocular trauma. Trans Ophthalmol Soc UK 1975;95:307-10.

2 Koval R, Teller J, Belkin M, et al. The Israeli ocular injuries Koval R, Teller J, Belkin M, et al. The Isra
study. Arch Ophthalmol 1988;106:776-80.

3 MacEwen CJ. Eye injuries; a prospective survey of 5671 MacEwen CJ. Eye injuries; a prospective
cases. Br f Ophthalmol 1989;73:888-94.
4 Schrader W. Perforating injuries: causes and risks are changing: a retrospective study. Ger f Ophthalmol 1993;2:
$6-82$.

5 Wykes WN. A 10-year survey of penetrating eye injuries in Gwent. Br F Ophthalmol 1988;72:607-11.

6 Viano DC, King AI, Melvin JW, et al. Injury biomechanics research: an essential element in the prevention of trauma. f Biomech 1989;22:403-17.

7 Nash IS, Greene PR, Foster CS. Comparison of mechanical properties of keratoconus and normal corneas. Exp Eye Res 1982;35:413-23.

8 Buzard KA. Introduction of biomechanics of the cornea. Refract Corneal Surg 1992;8:127-38.

9 Battaglioli, JL, Kamm RD. Measurement of the compressive properties of scleral tissue. Invest Ophthalmol Vis Sci 1984; 25:59-65.

10 Greene PR. Closed-form ametropic pressure-volume and ocular rigidity solutions. Am f Optom Physiol Opt 1985;62: $870-8$.

11 Hoeltzel DA, Altman P, Buzard K, et al. Strip extensiometry for comparison of the mechanical response of bovine, rabbit, and human corneas. F Biomech Eng 1992;114:202-15.

12 Hogan MJ, Alvarado JA, Weddell JE. In: Histology of the human eye. Philadelphia: Saunders, 1971:638-77.

13 Reichel E, Miller D, Blanco E, et al. The elastic modulus of central and perilimbal bovine cornea. Ann Ophthalmol 1989;21:205-8

14 Altair Engineering, Ltd. Hypermesh user's manual. Tokyo, Japan, 1996.

15 Makita, Corp. Makita product catalogue. Aichi, Japan, 1996.

16 Ryobi, Co Ltd. Ryobi product catalogue. Tokyo, Japan, 1997.

17 Kuhn F, Morris R, Witherspoon CD, et al. A standardized classification of ocular trauma. Ophthalmology 1996;103: $240-3$.

18 Hanna KD, Jouve FE, Waring GO, et al. Computer simulation of arcuate and radial incisions involving the corneoscleral limbus. Eye 1989;3:227-39.

19 Carnell PH, Vito RP. A model for estimating corneal stiffness using an indenter. F Biomech Eng 1992;114:54952.

20 Vito RP, Shin TJ, McCarey BE. A mechanical model of the cornea: the effects of physiological and surgical factors on radial keratotomy surgery. Refract Corneal Surg 1989;5:82-

$21 \mathrm{Ku} \mathrm{D}$, Greene PR. Scleral creep in vitro resulting from cyclic pressure pulses: applications of myopia. Am f Optom Physiol Opt 1981;58:528-35.

22 Taber LA. Large deformation mechanics of the enucleated eyeball. F Biomech Eng 1984;106:229-34.

23 Canavan YM, O'Flaherty MJ, Archer B, et al. A 10-year survey of eye injuries in Northern Ireland, 1967-76. Br f Ophthalmol 1980;64:618-25.

24 Liggett PR, Pince KJ, Barlow W, et al. Ocular trauma in an urban population. Ophthalmology 1990;97:581-4.

25 Saari KM, Parvi V. Occupational eye injuries in Finland. Acta Ophthalmol 1984;161Suppl: 17-28.

26 Hassat PD, Kelleher CC. The epidemiology of occupational penetrating eye injuries in Ireland. Occup Med 1994;44. 209-11. 